\title{
ANALISIS ASPEK TEKNIS DAN FINANSIAL PENGEMBANGAN USAHA TERNAK ITIK PETELUR (STUDI KASUS PADA CV. GIGA UNGGAS SATRIA DESA LAMBARO SUKON KECAMATAN LAMBARO ANGAN KABUPATEN ACEH BESAR)
}

\author{
Technical and Financial Aspects Feasibility Analysis of Laying Ducks Livestock \\ Business (Case Study at CV. Giga Unggas Satria Lambaro Sukon, Lambaro \\ Angan District, Aceh Besar Regency)
}

\author{
Cut Zulfah, Sofyan ${ }^{1}$, Irwan A. Kadir ${ }^{*}$ \\ ${ }^{1}$ Program Studi Agribisnis, Fakultas Pertanian, Universitas Syiah Kuala
}

\begin{abstract}
Abstrak. Itik termasuk komoditas peternakan yang mempunyai nilai ekonomis dan potensi yang sangat menjanjikan untuk dikembangkan, baik untuk memenuhi kebutuhan hewani maupun penunjang pendapatan keluarga maupun bisnis. Perkembangan peternakan itik di Indonesia terus meningkat setiap tahunnya dikarenakan meningkatnya jumlah permintaan masyarakat terhadap telur itik Adapun permasalahan yang terdapat dalam penelitian ini adalah apakah usaha ternak itik petelur di CV. Giga Unggas Satria layak diusahakan bila ditinjau dari aspek teknis dan aspek finansial. Penelitian ini bertujuan untuk mengetahui kelayakan aspek teknis dan finansial pengembangan usaha ternak itik di CV. Giga Unggas Satria. Usaha peternakan itik petelur pada CV. Giga Unggas Satria merupakan suatu unit usaha yang menekuni bidang ternak itik petelur jenis hibrida, dimana tujuan didirikan peternakan ini adalah untuk meningkatkan pendapatan peternak. Penelitian ini dilakukan di CV. Giga Unggas Satria Desa Lambaro Sukon Kecamatan Darussalam Kabupaten Aceh Besar. Penentuan lokasi penelitian dilakukan dengan sengaja (purposive). Metode yang digunakan dalam penelitian ini adalah analisis kualitatif dan kuantitatif. Analisis kualitatif (deskriptif) yaitu mendefenisikan gambaran umum perusahaan. Sedangkan analisis kuantitatif (statistik) yaitu menganalisis kelayakan finansial berdasarkan kriteria yang digunakan dalam studi kelayakan pada CV. Giga Unggas Satria. Metode analisis yang digunakan dalam penelitian ini analisis kriteria kelayakan investasi, yaitu analisis Net B/C, BEP, NPV, IRR, dan analisis sensitivitas. Hasil penelitian menunjukkan bahwa usaha peternakan itik di CV. Giga Unggas Satria layak di usahakan ditinjau dari aspek teknis dan finansial. Hal ini ditunjukkan dari hasil perhitungan diperoleh nilai NPV $=$ Rp 187.954.290; $\mathrm{Net} B / \mathrm{C}=2,73$ dan $\mathrm{IRR}=48,32 \%$. Hasil perhitugan analisis sensitivitas menunjukkan bahwa apabila biaya produksi naik $10 \%$ dan benefit tetap, usaha peternakan itik petelur di CV. Giga Unggas Satria tetap layak diusahakan, karena memperoleh nilai $\mathrm{NPV}=\mathrm{Rp} 27.393 .814, \mathrm{Net} \mathrm{B} / \mathrm{C}=1,16, \mathrm{IRR}=19,32 \%$. Selanjutnya BEP produksi telur mencapai 1.301.301 butir, dan BEP harga yaitu Rp Rp 1.543 per butir. Untuk kemungkinan yang kedua yaitu apabila benefit turun $10 \%$ dan biaya tetap, diperoleh NPV $=\mathrm{Rp} 8.598 .385$, Net $\mathrm{B} / \mathrm{C}=1,05, \mathrm{IRR}=$ $12,55 \%$. Selanjutnya BEP produksi telur mecapai 1.136 .129 butir, dan BEP harga yaitu Rp 1.347 per butir.
\end{abstract}

Kata kunci: Kelayakan Finansial, Itik Petelur, Telur Itik.

Abstract. Ducks include livestock commodities that have economic value and very promising potential to be developed, both to meet animal needs and to support family and business income. The development of duck farming in Indonesia continues to increase every year due to the increasing number of community demand for duck eggs. The problem found in this study is whether laying duck business in CV. Satria Poultry Giga is worthy of effort if viewed from the technical and financial aspects. This study aims to determine the feasibility of technical and financial aspects of duck business development in CV. Giga Poultry Satria. Laying duck farms on CV. Satria Giga Unggas is a business unit that engages in hybrid type laying duck fields, where the purpose of establishing this farm is to increase farmers' income. This research was conducted at CV. Satria Giga Poultry Lambaro Sukon Village Darussalam District Aceh Besar District. Determination of the location of the research was carried out deliberately (purposive). The method used in this study is

*Corresponding author: irwanakadir@unsyiah.ac.id 
qualitative and quantitative analysis. Qualitative analysis (descriptive) that defines the general description of the company. While quantitative analysis (statistics) is analyzing financial feasibility based on the criteria used in the feasibility study on the CV. Giga Poultry Satria. The analytical method used in this study analyzes the investment feasibility criteria, namely Net B / C, BEP, NPV, IRR, and sensitivity analysis. The results showed that duck farming in CV. Satria Giga Poultry is worthy of effort in terms of technical and financial aspects. This is shown from the calculation results obtained by the NPV value $=\operatorname{Rp} 187,954,290 ;$ Net B $/ C=2.73$ and IRR $=48.32 \%$. The results of the sensitivity analysis show that if the production costs increase by $10 \%$ and the benefits remain, the laying duck farming business on the CV. Poultry Giga Satria remains viable, because it obtains $\mathrm{NPV}$ value $=$ Rp. $27,393,814$, Net $\mathrm{B} / \mathrm{C}=1.16, \mathrm{IRR}=19.32 \%$. Furthermore, the egg production BEP reached 1,301,301 points, and the BEP price was Rp. 1,543 per item. For the second possibility, if the benefits decrease by $10 \%$ and the fixed costs, NPV $=$ Rp. 8,598,385, Net B / C $=1.05$, IRR = $12.55 \%$. Furthermore, the egg production BEP reached 1,136,129 items, and BEP prices were Rp 1,347 per item.

Key Words: Financial Feasibility, laying ducks, duck eggs

\section{PENDAHULUAN}

Itik termasuk komoditas peternakan yang mempunyai nilai ekonomis dan potensi yang sangat menjanjikan untuk dikembangkan, baik untuk memenuhi kebutuhan hewani maupun penunjang pendapatan keluarga maupun bisnis. Perkembangan peternakan itik di Indonesia terus meningkat setiap tahunnya dikarenakan meningkatnya jumlah permintaan masyarakat terhadap telur itik (Ahmad, 2010). Usaha peternakan itik petelur sangat diminati oleh masyarakat sebagai salah satu usaha penunjang dalam meningkatkan pendapatan serta sebagai sarana investasi baik sebagai usaha sampingan ataupun usaha utama. Besarnya peluang ternak itik ini tentu sebagai alasan utama, baik peternakan unggas petelur, pedaging maupun pembibitan, hingga sampai ke hilir yaitu usaha pembuatan telur asin.

Usaha peternakan itik petelur pada CV. Giga Unggas Satria merupakan suatu unit usaha yang menekuni bidang ternak itik petelur jenis hibrida dengan populasi yaitu 2.078 ekor itik betina dan 22 ekor itik jantan. Itik hibrida merupakan itik hasil perkawinan silang dari dua jenis itik yang dipelihara yaitu dari persilangan itik Mojosari dengan itik Peking yang bertujuan mendapatkan keturunan yang mewarisi sifat baik indukan jantan dan betinanya. Usaha itik ini sudah ditekuni sejak akhir tahun 2014, dimana tujuan didirikan peternakan ini adalah untuk meningkatkan pendapatan peternak. Dalam proses pemeliharaan itik tersebut, usaha peternakan itik bukan tanpa masalah. Fenomena yang terjadi secara umum adalah disamping prospeknya yang cerah tetapi juga memerlukan biaya yang tinggi untuk setiap periode produksinya. Biaya yang paling banyak adalah biaya untuk pakan ternak. Menurut Destiana (2010) pemeliharaan itik intensif $60-70 \%$ biaya produksi dipengaruhi oleh biaya pakan. Karena itu dibutuhkan biaya investasi yang cukup besar. CV. Giga Unggas Satria berharap setiap tahunnya dapat menambahkan jumlah kandang dengan kapasitas itik yang lebih besar lagi disetiap tahunnya, namun harapan itu belum tercapai sepenuhnya sesuai dengan apa yang telah direncanakan sebelumnya. Kondisi ini terjadi disebabkan oleh harga pakan yang mahal.

Berdasarkan uraian diatas, penulis tertarik untuk melakukan penelitian mengenai "Analisis Aspek Teknis dan Finansial Pengembangan Usaha Ternak Itik

Analisis Aspek Teknis dan Finansial Pengembangan Usaha Ternak Itik Petelur (Studi Kasus 
Petelur Pada CV. Giga Unggas Satria Kabupaten Aceh Besar”. Berdasarkan uraian di atas, maka perumusan masalahnya, yaitu bagaimana kelayakan aspek teknis dan finansial pengembangan usaha ternak itik di CV. Giga Unggas Satria. Tujuan dari penelitian ini untuk mengetahui kelayakan aspek teknis dan finansial pengembangan usaha ternak itik di CV. Giga Unggas Satria.

\section{METODE PENELITIAN}

Penelitian ini dilakukan di CV. Giga Unggas Satria Desa Lambaro Sukon Kecamatan Darussalam Kabupaten Aceh Besar. Penentuan lokasi penelitian dilakukan dengan sengaja (purposive). Penelitian ini dilaksanakan pada bulan Desember 2017. Objek dalam penelitian ini adalah peternak pada peternakan yang ada di Desa Lambaro Sukon Kecamatan Darussalam Kabupaten Aceh Besar. Sedangkan ruang lingkup penelitian ini terbatas pada aspek teknis dan finansial pengembangan usaha ternak itik petelur yang meliputi input produksi, biaya, penerimaan, serta pendapatan.

Metode yang digunakan dalam penelitian ini adalah analisis kualitatif dan kuantitatif. Analisis kualitatif (deskriptif) yaitu mendefenisikan gambaran umum perusahaan. Sedangkan analisis kuantitatif (statistik) yaitu menganalisis kelayakan finansial berdasarkan kriteria yang digunakan dalam studi kelayakan pada CV. Giga Unggas Satria. Metode analisis yang digunakan dalam penelitian ini analisis kriteria kelayakan investasi, yaitu analisis Net B/C, BEP, NPV, IRR,dan analisis sensitivitas. Untuk identifikasi masalah diuji dengan metode analisis Net B/C, BEP, NPV, IRR, dan analisiss sensitivitas yang mana mengidentifikasi kelayakan usaha ternak itik dilihat dari titik impas, jumlah pendapatan yang diterima, dan tingkat kembalinya modal.

\section{a. Net Benefit Cost Ratio (Net B/C)}

Net Benefit Cost Ratio (Net B/C) merupakan perbandingan antara nilai NPV positif dengan NPV negatif. Untuk menghitung Net B/C dapat digunakan rumus berikut:

$$
\text { Net } \mathrm{B} / \mathrm{C}=\frac{\sum_{t=0}^{t=n} N P V \text { Positif }}{\sum_{t=0}^{t=n} N P V \text { Negatif }}
$$

Dengan kriteria:

Net $\mathrm{B} / \mathrm{C}>1$, proyek layak diusahakan

Net $B / C=1$, proyek tidak menguntungkan dan tidak merugikan

Net $\mathrm{B} / \mathrm{C}<1$, proyek tidak layak diusahakan

\section{b. BEP (Break Event Point)}

BEP merupakan alat analisis yang digunakan untuk mengetahui batas nilai produksi atau volume produksi suatu usaha mencapai titik impas, yaitu tidak untung dan tidak rugi. Untuk memghitumh nilai BEP maka digunakan rumus sebagai berikut:

$$
\mathrm{BEP} \text { Produksi }=\frac{\text { Biaya Produksi }(\mathrm{Rp})}{\text { Harga Jual }(\mathrm{Rp})}
$$

Analisis Aspek Teknis dan Finansial Pengembangan Usaha Ternak Itik Petelur (Studi Kasus 


$$
\begin{gathered}
\text { dan } \\
\text { BEP Harga }=\frac{\text { Biaya Produksi (Rp) }}{\text { Jumlah Produksi }}
\end{gathered}
$$

Kriteria penilaian BEP : Apabila penjualan atau produksi melebihi penjualan atau produksi pada saat mencapai titik impas, maka usaha tersebut telah mendatangkan keuntungan sehingga layak untuk diusahakan (Soekartawi, 2002).

c. Net Present Value (NPV)

NPV merupakan selisih antara pengeluaran dan pemasukan yang telah didiskon dengan menggunakan social opportunity cost of capital sebagai diskon factor. Dirumuskan sebagai berikut:

$$
\mathrm{NPV}=\sum_{t=0}^{t=n} \frac{(\mathrm{Bt}-\mathrm{Ct})}{(1+i)^{t}}
$$

Dimana:

$\mathrm{B}_{\mathrm{t}} \quad=$ Benefit pada tahun ke- $\mathrm{t}$

$\mathrm{C}_{\mathrm{t}} \quad=$ Biaya pada tahun ke- $\mathrm{t}$

$\mathrm{i} \quad=$ Tingkat suku bunga yang berlaku yaitu $9 \%$

$\mathrm{t} \quad=$ Lamanya periode waktu

Dengan kriteria:

NPV > 0, proyek layak diusahakan

$\mathrm{NPV}=0$, proyek tidak layak diusahakan

$\mathrm{NPV}>0$, proyek tidak layak diusahakan

d. Internal Rate of Return (IRR)

IRR merupakan suatu nilai petunjuk yang identik dengan seberapa besar suku bunga yang dapat dihasilkan oleh investasi tersebut dibandingkan dengan suku bunga bank yang berlaku umum (suku bunga pasar atau Minimum Attractive Rate of Return/MARR). Untuk bisa memperoleh hasil akhir dari IRR kita harus mencari discount rate yang menghasilkan NPV positif, kemudian setelah itu cari discount rate yang menghasilkan NPV negative, maka IRR dirumuskan sebagai berikut:

$\operatorname{IRR}=\mathrm{i}_{1}+\frac{N P V_{1}}{(N P V 1-N P V 2)}\left(\mathrm{i}_{2}-\mathrm{i}_{1}\right)$

Dimana:

$\mathrm{i}_{1} \quad=$ Tingkat Diskonto yang menghasilkan NPV+

$\mathrm{i}_{2} \quad=$ Tingkat Diskonto yang menghasilkan NPV-

$\mathrm{NPV}_{1}=$ Net Present Value bernilai positif

$\mathrm{NPV}_{2}=$ Net Present Value bernilai negative.

Dengan kriteria:

IRR > i, layak diusahakan

$\mathrm{IRR}=\mathrm{i}$, layak diusahakan

Analisis Aspek Teknis dan Finansial Pengembangan Usaha Ternak Itik Petelur (Studi Kasus 
IRR $<$ i, tidak layal diusahakan

\section{e. Analisis Sensitivitas}

Analisis sensitivitas bertujuan untuk mengetahui kemungkinan yang terjadi jika ada kesalahan dalam perhitungan baik pada biaya maupun manfaat serta perubahan-perubahan yang tidak diduga sebelumnya. Dalam perhitungan ini digunakan asumsi sebagai berikut:
a. Biaya produksi naik $10 \%$, benefit tetap
b. Biaya produksi tetap, benefit turun $10 \%$

\section{HASIL PENELITIAN DAN PEMBAHASAN}

\section{Profil Usaha}

CV. Giga Unggas Satria merupakan salah satu perusahaan yang bergerak pada peternakan itik petelur, dimana peternakan ini berdiri sejak tahun 2014 yang dikelola oleh Bapak Gian Satria di Desa Lambaro Sukon Kecamatan Lambaro Angan Kabupaten Aceh Besar. Peternakan ini berfokus pada menghasilkan telur itik secara optimal sehingga memilih untuk memelihara itik dara yang siap untuk menghasilkan telur. Populasi itik di Peternakan itik CV. Giga Unggas Satria yaitu 2.100 ekor. Pada saaat ini, CV. Giga Unggas Satria memiliki 2.078 ekor itik betina dan 22 ekor itik jantan, jenis itik yang dipelihara yaitu jenis hibrida dari persilangan itik Mojosari dengan itik Peking.

\section{Aspek Teknis Usaha \\ Lokasi Peternakan}

Sebelum usaha beternak dimulai, seorang peternak harus mempertimbangkan lokasi pemeliharaan itik terlebih dahulu agar usaha tersebut memperoleh keuntumgan yang optimal. Adapun lokasi usaha peternakan CV. Giga Unggas Satria yaitu:

a. Lokasi jauh dari suara gaduh, karena itik termasuk ternak yang peka terhadap kegaduhan yang akan berpengaruh terhadap produksi telur.

b. Lokasi perkandangan tidak terlalu dekat dengan pemukiman, sebab akan menimbulkan bau yang tidak sedap terhadap pemukiman.

c. Dekat dengan sumber air dan sumber pakan alami

d. Mudah dijangkau dengan transportasi

e. Lokasi pemasaran telur itik dari tempat usaha yaitu $\pm 4-8 \mathrm{Km}$.

\section{Perkandangan}

Kandang yang digunakan untuk memelihara itik merupakan kandang berjenis postal litter yaitu bangunan kandang yang beralaskan lantai yang di semen dan diberi alas sekam padi. Disekeliling kandang diberi kawat agar itik tidak terganggu dari binatang buas dan kegiatan manusia. Kadang pada CV. Giga Unggas Satria postal memiliki ukuran total $66 \mathrm{~m} \times 12 \mathrm{~m}$ yang dapat menampung 2.100 ekor itik. Kandang tersebut terdiri dari dua bangunan yang dibagi menjadi 11 petak dengan ukuran per petak $6 \mathrm{~m}$ x $12 \mathrm{~m}$ untuk 200 ekor itik.

Analisis Aspek Teknis dan Finansial Pengembangan Usaha Ternak Itik Petelur (Studi Kasus 486 Pada CV. Giga Unggas Satria Desa Lambaro Sukon Kecamatan Lambaro Angan Kabupaten Aceh Besar), (Cut Zulfah, Irwan A. Kadir, Sofyan) 


\section{Pakan}

Bahan utama yang digunakan dalam usaha ternak itik yaitu pakan ternak. Dalam usaha ternak itik, pakan ternak yang digunakan pada CV. Giga Unggas Satria antara lain enceng gondok, konsentrat (HI-PRO-VITE 124), dan mineral (Turbo). Peternak yang membutuhkan pakan dalam jumlah yang banyak sudah berlangganan sebelumnya dengan sistem barang diantar ketempat.

Jadwal pemberian pakan itik pada CV. Giga Unggas Satria dua kali sehari yaitu pada pagi dan sore, serta pemberian mineral pada siang hari agar memperoleh hasil telur yang baik. Jam pemberian pakan harus tepat waktu dan tidak boleh berubah-ubah setiap harinya. Jam pemberian pakan dan mineral pada itik dapat dibagi menjadi tiga waktu yaitu:

a. Pemberian pakan konsentrat pada pagi hari jam 06.30 WIB

b. Pemberian mineral pada siang hari jam $11.00 \mathrm{WIB}$

c. Pemberian pakan enceng gondok pada sore hari jam $15.00 \mathrm{WIB}$

Bibit

CV. Giga Unggas Satria membeli itik dara siap bertelur agar lebih efesiensi waktu dan biaya. Bibit yang dibeli berumur 4 bulan dengan bobot 1,4-1,5 kg jenis hibrida hasil persilangan itik Mojosari dengan itik Peking. Produksi telur pertahun rata-rata mencapai 200 - 250 butir telur. Bibit itik didapatkan dengan melakukan pembelian langsung ke peternakan tempat penjualan bibit itik.

\section{Pengeluaran}

\section{Biaya Investasi}

Biaya investasi adalah seluruh biaya yang dilkeluarkan dari mulai usaha tersebut di laksanakan sampai dengan usaha tersebut mulai berjalan, atau dengan kata lain biaya investasi merupakan biaya awal yang digunakan untuk membeli barang-barang modal selama usaha tersebut belum menghasilkan. Biaya ini meliputi pembelian lahan, pembangunan kandang, dan pembelian peralatan. Biaya ini hanya dikeluarkan pada tahun pertama usaha dijalankan. Untuk mengetahui biaya investasi usaha ternak itik petelur dapat dilihat pada Tabel 1 berikut.

Tabel 1. Biaya Investasi Usaha Ternak Itik Petelur Pada Peternakan CV. Giga Unggas Satria

\begin{tabular}{llcccrr}
\hline No & Biaya Investasi & Jumlah & $\begin{array}{c}\text { Umur } \\
\text { Ekonomis }\end{array}$ & Satuan & $\begin{array}{c}\text { Harga } \\
(\mathbf{R P} / \mathbf{s a t u a n})\end{array}$ & $\begin{array}{c}\text { Jumlah Nilai } \\
(\mathbf{R p})\end{array}$ \\
\hline 1 & Kandang & 1 & 15 & unit & $68,898,000$ & $68,898,000$ \\
2 & Tempat Pakan & 22 & 3 & unit & 20,000 & 440,000 \\
3 & Tempat Minum & 11 & 3 & unit & 20,000 & 220,000 \\
4 & Sumur & 1 & 15 & unit & $4,493,000$ & $4,493,000$ \\
5 & Selang & 1 & 5 & unit & 350,000 & 350,000 \\
6 & Mesin pompa & 1 & 6 & unit & 450,000 & 450,000 \\
7 & air & 6 & 2 & unit & 24,000 & 144,000 \\
\hline
\end{tabular}

Sumber: Data primer (diolah), 2017

Analisis Aspek Teknis dan Finansial Pengembangan Usaha Ternak Itik Petelur (Studi Kasus 


\section{Biaya Operasional}

a. Biaya Operasional Tidak Tetap

Biaya operasional tidak tetap merupakan biaya yang dikeluarkan untuk membeli bahan baku, dimana bahan baku terdiri bibit itik, pakan, obat-obatan, dan sekam padi. Adapun besarnya biaya operasional penggunaan bahan baku yang dikeluarkan untuk ternak itik petelur oleh CV. Giga Unggas Satria dapat dilihat pada Tabel 2.

Tabel 2. Biaya Operasional Tidak Tetap Ternak Itik Petelur Pada Peternakan CV. Giga Unggas Satria

\begin{tabular}{rlrcrr}
\hline No & Uraian & Jumlah & $\begin{array}{c}\text { Satuan Per } \\
\text { Tahun }\end{array}$ & $\begin{array}{c}\text { Harga } \\
\text { (Rp/satuan) }\end{array}$ & \multicolumn{1}{c}{ Total (Rp) } \\
\hline 1 & Bibit itik & 2.100 & Ekor & 55.000 & 115.500 .000 \\
2 & Pakan & 80.300 & Kg & 6.000 & 481.800 .000 \\
3 & Obat-obatan & $2.007,5$ & Kg & 6.000 & 12.045 .000 \\
\hline & Jumlah & & & & 609.345 .000
\end{tabular}

Sumber: Data primer (diolah), 2017

b. Biaya Operasional Tetap

Tabel 3. Biaya Operasional Tetap Usaha Ternak Itik Petelur Pada Peternakan CV. Giga Unggas Satria

\begin{tabular}{rlrrr}
\hline No. & \multicolumn{1}{c}{ Uraian } & \multicolumn{1}{c}{$\begin{array}{c}\text { Harga } \\
\text { (Rp/Bulan) }\end{array}$} & $\begin{array}{c}\text { Jumlah Nilai } \\
\text { (Rp/Bulan) }\end{array}$ & \multicolumn{1}{c}{$\begin{array}{c}\text { Jumlah Nilai } \\
\text { (Rp/Tahun) }\end{array}$} \\
\hline 1 & Sewa Lahan & & & $3,000,000$ \\
2 & Listrik & 120,000 & 120,000 & $1,440,000$ \\
3 & Tenaga Kerja (3 Orang) & $2,000,000$ & $6,000,000$ & $72,000,000$ \\
4 & Transportasi & 30,000 & 300,000 & $3,600,000$ \\
\hline & Jumlah & & $6,420,000$ & $80,040,000.00$ \\
\hline
\end{tabular}

Sumber: Data primer (diolah), 2017

c. Biaya Penyusutan Peralatan

Biaya penyusutan yang dikeluarkan oleh CV. Giga Unggas Satria mencapai Rp 4.803.960 per tahun yang terdiri dari kandang, tempat makan, tempat minum, selang, mesin pompa air, dan bola lampu. Adapun biaya penyusutan terbesar yaitu kandang sebesar Rp 4.133.880 per tahun untuk satu unit, dan biaya penyusutan terkecil yaitu selang air sebanyak satu unit yaitu Rp 63.000 per tahun.

\section{Produksi, Nilai Produksi dan Pendapatan}

Produksi adalah kegiatan yang dapat menimbulkan tambahan manfaat atau faedah baru (Ahyari, 2011). Produksi merupakan kegiatan yang cukup penting, Karena apabila kegiatan produksi terhenti maka kegiatan dalam usaha akan terhenti pula. Jumlah produksi yang dihasilkan pada usaha CV. Giga Unggas Satria dapat dilihat pada Tabel 4. 
Tabel 4. Jumlah Produksi dan Harga Jual Telur Itik selama 3 Tahun (2015 -2017)

\begin{tabular}{cccr}
\hline $\begin{array}{c}\text { Tahun } \\
\text { Ke }\end{array}$ & $\begin{array}{c}\text { Jumlah } \\
\text { (Butir/tahun) }\end{array}$ & $\begin{array}{c}\text { Harga } \\
\text { (Rp/Butir) }\end{array}$ & \multicolumn{1}{c}{$\begin{array}{c}\text { Jumlah Nilai } \\
\text { (Rp/Tahun) }\end{array}$} \\
\hline 1 & 427.656 & 1.400 & 598.718 .400 \\
2 & 457.466 & 1.600 & 731.945 .600 \\
3 & 464.471 & 1.600 & 743.153 .600 \\
\hline Jumlah & 1.349 .593 & & 2.073 .817 .600 \\
\hline
\end{tabular}

Sumber: Data primer (diolah), 2017

\section{Analisis Kriteria Kelayakan Investasi}

Analisis kriteria kelayakan investasi yang digunakan untuk menilai usaha ternak itik adalah Net Present Value (NPV), Net Benefit Cost Ratio (Net B/C), Internal Rate of Return (IRR), Break Event Point (BEP). Adapun hasil perhitungan kriteria kelayakan investasi CV. Giga Unggas Satria yaitu usaha ternak itik di CV. Giga Unggas Satria Desa Lambaro Sukon Kecamatan Lambaro Angan Kabupaten Aceh Besar layak dijalankan. Hal ini dikarenakan nilai NPV > 0, yaitu sebesar Rp 187.954.290 yang berarti penerimaan lebih besar daripada biaya yang dikeluarkan. Net B/C > 1, yaitu 2,73 yang berarti setiap penambahan biaya Rp 1,- maka akan memperoleh keuntungan sebesar Rp 2,73. IRR > tingkat suku bunga yang berlaku yaitu sebesar 48,32\% per tahun. Sedangkan BEP produksi telur yaitu 1.136.128 butir, dan BEP harga yaitu Rp Rp 1.346 per butir.

\section{Analisis Sensitivitas}

Dalam merencanakan suatu proyek, semua biaya yang akan dikeluarkan setiap tahun diperkirakan berdasarkan tingkat suku bunga yang diperoleh dari proyek tersebut. Dengan demikian bisa saja terjadi kekeliruan atau tidak tepatnya perkiraan biaya yang telah disusun. Analisis sensitivitas bertujuan untuk melihat apa yang akan terjadi dengan analisis proyek jika terdapat suatu kesalahan ataupun perubahan dalam perhitungan biaya atau benefit. Adapun asumsi dan kemungkinan yang akan di analisis dalam penelitian ini adalah:

1. Biaya produksi naik $10 \%$ dari perkiraan semula, sedangkan benefit tetap.

2. Biaya produksi tetap, tetapi benefit turun sebesar $10 \%$.

Berdasarkan kemungkinan-kemungkinan tersebut diatas, maka diperoleh hasil analisis sebagai berikut:

Kemungkinan I

Biaya produksi naik $10 \%$ dari perkiraan semula, sedangkan penerimaan tetap. Kenaikan biaya produksi sebesar $10 \%$ akan membuat biaya yang semula Rp 1.817.806.250 berubah menjadi 2.082.081.375. Adapun hasil perhitungan analisis sensitivitas tersebut dapat dilihat pada Tabel 5. 
Tabel 5. Hasil Analisis Sensitivitas Terhadap Kenaikan Biaya Produksi Sebesar 10\% dan Benefit Tetap Pada CV. Giga Unggas Satria

\begin{tabular}{clcc} 
No & Kriteria Kelayakan Investasi & Hasil Analisis & Keterangan \\
\hline 1 & NPV (Net Present Value) & Rp 27.393.814 & Layak \\
2 & Net B/C (Net Benefit Cost Ratio) & 1,16 & Layak \\
3 & IRR (Internal Rate of Return) & $19,32 \%$ & Layak \\
4 & BEP (Break Even Point) Produksi & 1.301 .301 butir & \\
5 & BEP (Break Even Point) Harga & Rp 1.543/butir & \\
\hline
\end{tabular}

Sumber: Data primer (diolah), 2017

Berdasarkan hasil analisis sensitivitas pada Tabel 5, dapat diketahui bahwa usaha ternak itik CV. Giga Unggas Satria pada keadaan biaya produksi naik 10\% sedangkan benefit tetap diperoleh NPV > 0 yaitu sebesar Rp 27.393.814, Net B/C $>1$ yaitu sebesar 1,16, artinya setiap penambahan biaya $\mathrm{Rp} 1$, maka akan diperoleh keuntungan sebesar Rp 1,16. IRR > tingkat suku bunga yang berlaku yaitu sebesar $19,32 \%$. Selanjutnya BEP produksi telur yaitu 1.301.301 butir, dan BEP harga yaitu Rp Rp 1.543 per butir. Hal ini menunjukkan bahwa usaha ternak itik CV. Giga Unggas Satria layak untuk dijalankan meskipun biaya produksi naik $10 \%$ dan benefit yang diterima tetap.

\section{Kemungkinan II}

Penerimaan turun $10 \%$ dari perkiraaan semula, sedangkan biaya produksi tetap. Penurunan benefit sebesar $10 \%$ akan membuat jumlah penerimaan semula Rp 2.144.217.003 berubah menjadi $\mathrm{Rp}$ 1.929.795.303. Adapun hasil perhitungan analisis sensitivitas tersebut dapat dilihat pada Tabel 9.

Tabel 6. Hasil Analisis Sensitivitas Terhadap Kenaikan Biaya Produksi Sebesar $10 \%$ dan Benefit Tetap Pada CV. Giga Unggas Satria

\begin{tabular}{clcc} 
No & Kriteria Kelayakan Investasi & Hasil Analisis & Keterangan \\
\hline 1 & NPV (Net Present Value) & Rp 8.598.385 & Layak \\
2 & Net B/C (Net Benefit Cost Ratio) & 1,05 & Layak \\
3 & IRR (Internal Rate of Return) & $12,55 \%$ & Layak \\
4 & BEP (Break Even Point) Produksi & 1.136 .129 butir & \\
5 & BEP (Break Even Point) Harga & Rp 1.347/butir & \\
\hline
\end{tabular}

Sumber: Data primer (diolah), 2017

Berdasarkan hasil analisis sensitivitas pada Tabel 6, dapat diketahui bahwa usaha ternak itik CV. Giga Unggas Satria pada keadaan benefit turun $10 \%$ sedangkan biaya produksi tetap diperoleh NPV > 0 yaitu sebesar Rp 8.598.385, Net $\mathrm{B} / \mathrm{C}>1$ yaitu sebesar 1,05, artinya setiap penambahan biaya Rp 1, maka akan diperoleh keuntungan sebesar Rp 1,05. IRR > tingkat suku bunga yang berlaku yaitu sebesar $12,55 \%$. Selanjutnya BEP produksi telur yaitu 1.136 .129 butir, dan BEP harga yaitu Rp Rp 1.347 per butir. Hal ini menunjukkan bahwa usaha ternak itik CV. Giga Unggas Satria layak untuk dijalankan meskipun pada keadaan benefit turun $10 \%$ sedangkan biaya produksi tetap.

Analisis Aspek Teknis dan Finansial Pengembangan Usaha Ternak Itik Petelur (Studi Kasus 490 Pada CV. Giga Unggas Satria Desa Lambaro Sukon Kecamatan Lambaro Angan Kabupaten Aceh Besar), (Cut Zulfah, Irwan A. Kadir, Sofyan) 
Dengan demikian, hasil yang diperoleh dari perhitungan analisis sensitivitas menunjukkan bahwa usaha ternak itik pada CV. Giga Unggas Satria masih layak dijalankan, baik dengan kemungkinan biaya naik 10\% sedangkan benefit tetap, maupun dengan kemungkinan benefit turun $10 \%$ sedangkan biaya produksi tetap.

\section{SIMPULAN DAN SARAN}

\section{Simpulan}

Berdasarkan hasil dan pembahasan pada penelitian ini, dapat disimpulkan sebagai berikut:

1. Peternakan CV. Giga Unggas Satria Desa Lambaro Sukon Kecamatan Lambaro Angan Kabupaten Aceh Besar berdasarkan kriteria kelayakan investasi, usaha ini dinyatakan layak dimana nilai NPV (Net Present Value) sebesar Rp 187.954.290,- Net B/C (Net Benefit Cost Ratio) yaitu sebesar 2,73, IRR (Internal Rate of Return) sebesar 48,32\%, serta BEP (Break Even Point) produksi yaitu 1.136.128 butir dan BEP (Break Even Point) harga yaitu Rp Rp 1.346 per butirnya.

\section{Saran}

Berdasarkan simpulan diatas, dapat diberikan saran sebagai berikut:

1. Sebaiknya kondisi volume produksi peternakan harus diperhatikan lagi agar tidak terjadi penurunan volume produksi yang akan berdampak pada keuntungan yang tidak stabil. Dengan cara membeli pakan tepat waktu, sehingga tidak terputus pakan agar produksinya dapat ditingkatkan lagi.

2. Sebaiknya pemerintah harus dapat menjaga harga pakan ternak agar tidak membumbung tinggi, hal tersebut akan sangat memberatkan peternak mengingat biaya terbesar pada usaha ternak itik yaitu biaya untuk kebutuhan pakan ternak.

\section{DAFTAR PUSTAKA}

Abadi, M. 2017. Evaluasi Kelayakan Finansial Ayam Ras Petelur pada Cv. Bintani Poultry Shop Kendari. Buletin Peternakan Vol. 41 (3): 355-364, Agustus 2017 ISSN-0126-4400

Ahmad, 2010. Kelayakan Usaha Peternakan Itik Petelur Dengan Pemanfaatan Keong Mas Sebagai Sumber Pangan Alternative. Skripsi. Fakultas Ekonomi Dan Manajemen. Institute Pertanian Bogor. Bogor.

Alfikri, S. N. 2012. Studi Aspek Teknis Dan Finansial Pengembangan Usaha Ternak Itik Hibrida Pedaging di Peternakan Saonada Kabupaten Jombang. Fakultas Teknologi Pertanian Universitas Brawijaya, Malang.

Chaves dan Lasmini. 1978. Dalam: Sumantri. 2012. Upaya Teknis Peningkatan Populasi dan Produktivitas Itik. Balai Penelitian Ternak. Ciawi, Bogor.

Darliati. 2013. Analisis Usaha Dan Pemasaran Itik Pedaging Studi Kasus di Kleurahan Sail Kecamatan Tenayan Raya. Fakultas Pertanian Universitas Riau. 
Dramendra. 2015. Analisa Usaha Itik Petelur Di Desa Bangun Purba Timur Jaya Kecamatan Bangun Purba Kabupaten Rokan Hulu. Skripsi. Fakultas Pertanian Universitas Pasir Pengaraian, Riau.

Harahap, A. Arbi, A. Tami, D. Azhari, W. Dan Tan Bandaro, D. DT. 1978. Pengaruh Manajemen Terhadap Produksi Telur Itik di Sumatera Barat. Laporan Penelitian. Direktorat Pembinaan Penelitian dan Pengabdian Pada Masyarakat. Direktorat Jenderal Pendidikan dan Kebudayaan, Jakarta.

Herwin, O. 2005. Analisis Kelayakan Usaha Pembibitan Itik Di Desa Kagokan, Kecamatan Gatak, Kabupaten Sukoharjo, Jawa. Skripsi. Fakultas Peternakan, Institut Pertanian Bogor, Bogor.

Jumingan. 2009. Analisis Laporan Keuangan. Bumi Aksara, Surakarta.

Kadariah. 1986. Evaluasi Proyek Keputusan Investasi. PT Pustaka Binaman Pressindo, Jakarta.

Kasmir dan Jakfar. 2003. Studi Kelayakan Bisnis. Prenada Media, Jakarta.

Ketaren, P. 2002. Kebutuhan Gizi itik Petelur dan Itik Pedaging. WARTAZOA Vol. 12 No. 2 Th. 2002.

Mamarimbing, D. 2017. Analisis Manajemen Pemeliharaan Ternak Itik Petelur di Kecamatan Kakas Barat Kabupaten Minahasa. Jurnal Zootek ("Zootek" Journal ) Vol. 37 No. 2: 216 - 223, Juli 2017.

Soekartawi. 2002. Prinsip Dasar Ekonomi Pertanian Teori dan Aplikasi. PT. Raja Grafindo, Jakarta.

Suharda, Riki. 2015. Analisis Kelayakan Usaha Ternak Itik (Studi Kasus Desa Percut, Kec. Percut Sei Tuan, Kab. Deli Serdang). (Skripsi). Fakultas Pertanian Universitas Sumatera Utara, Medan.

Suharno, B. Dan Amri, K. 2002. Beternak Itik secara Intensif. Penebar Swadaya, Jakarta.

Umar, Husein. 2003. Studi Kelayakan Bisnis (Edisi 2), Teknik Menganalisis Kelayakan Rencana Bisnis secara Komprehensif. Gramedia Pustaka Utama, Jakarta.

Wakhid. 2010. Buku Pintar Beternak dan Bisnis Itik. Agro Media Pustaka, Jakarta. Wibowo, A. 2009. Analisis Usaha Ternak Itik di Kabupaten Sukoharjo. Skripsi. Fakultas Pertanian Universitas Sebelas Maret, Surakarta. 